\title{
Modelling energy savings in chicken meat osmotic dehydration process
}

\author{
Vladimir Filipović1, ${ }^{*}$, Marko Petković ${ }^{2}$, Ivana Filipović $^{1,3}$, and Jelena Filipović $^{4}$ \\ ${ }^{1}$ University of Novi Sad, Faculty of Technology, Bul. cara Lazara 1, Novi Sad, Serbia \\ ${ }^{2}$ University of Kragujevac, Faculty of Agronomy, Cara Dušana 34, Čačak, Serbia \\ ${ }^{3}$ SP Laboratory, Industrijska 3, Bečej, Serbia \\ ${ }^{4}$ University of Novi Sad, Institute for Food Technology, Bul. cara Lazara 1, Novi Sad, Serbia
}

\begin{abstract}
Osmotic dehydration is a low energy demanding process, and in order to investigate and estimate the energy efficiency of the osmotic dehydration process, convective drying is taken as a base treatment for comparison. Obtained energy savings data of the osmodehydration process are used to develop mathematical models of the energy savings of the process. Results showed that maximal quantity of heat saved, indicated on high levels of energy efficiency of chicken meat osmodehydration process, while both technological parameters statistically significantly influenced process energy efficiency. The developed mathematical the model, allows good prediction of the quantity of heat saved based on applied technological parameters.
\end{abstract}

\section{Introduction}

The production of chicken meat has undergone remarkable growth in recent years and as a result of the growth in demand, meat producers began to diversify their products with a view to increasing the value and an increase in shelf life [1].

Reducing the amount of consumed energy per unit of removed water from the food material is necessary for the effort to increase the total efficiency, reduce the costs of production, as well as reducing the effects of high energy consumption on the environment [2].

Osmotic dehydration is low energy demanding process $[3,4]$ due to its ability to remove water from the food material without phase change, hence without energy consumption on latent heat of evaporation of water $[5,6]$.

Osmotic dehydration is recognized as a pre-treatment step to meat drying processes such as air-drying, microwave or freeze-drying, to improve the nutritional, sensorial and functional properties of meats, reduce heat damage and minimize their colour and flavour changes [7].

Osmotic dehydration is important food preservation method in the food processing industry because of many advantages considering mild processing temperature, base waste material and low energy requirements [8].

\footnotetext{
*Corresponding author: vladaf@uns.ac.rs
} 
In order to investigate and estimate the energy efficiency of the osmotic dehydration process, convective drying is taken as a base treatment for comparison. Osmotic dehydration process and convective process efficiencies comparison are possible only by choosing the adequate response of both processes, where only water loss (WL) is not affected by solid gain, characteristicalmass transfer of the osmodehydration process.

The goal of this research is to estimate the energy efficiency of chicken meat osmotic process via comparison to the convective drying and to model obtained energy savings data of the osmodehydration process.

\section{Material and methods}

The raw skinless chicken breast meat was purchased just before use. The initial moisture content of the fresh chicken meat was $75.10 \pm 0.46 \%$. The osmotic solution used in this research was sugar beet molasses obtained from the sugar factory Pećinci, with initial dry matter content of $85.04 \%$, diluted to the mass concentration of $80 \%, 70 \%$, and $60 \%$ dry matter (d.m.) content.

Osmotic dehydration energy savings data are obtained via analyzing dynamics of water evaporation as described in [9]. The same quantities of chicken meat cube samples (dimensions of $1 \times 1 \times 1 \mathrm{~cm}$ ) and water of $100 \mathrm{~g}$ in the same glass trays were placed in a convective heater, preheated at $100^{\circ} \mathrm{C}$. The samples of meat and water were at the same room temperature before the experiment. In equal time intervals $(15 \mathrm{~min}, 30 \mathrm{~min}, 45 \mathrm{~min}$, $60 \mathrm{~min}, 90 \mathrm{~min}, 120 \mathrm{~min}$, and $150 \mathrm{~min}$ ) chicken meat and water sample mass are measured.

Calculation of WL values used for calculation of the quantity of saved energy is described in [10].

Quantity of heat $(Q)$ needed for increasing the temperature of water samples and evaporation of determined mass of water is calculated from the following equation [11]:

$$
Q=c_{p} \cdot m_{s} \cdot\left(T_{2}-T_{1}\right)+L \cdot m_{i}
$$

Where $c_{p}$ is specific heat capacity of the sample $(\mathrm{kJ} / \mathrm{kg} \cdot \mathrm{C}), m_{s}$ is sample mass $(\mathrm{kg}), T_{l}$ is initial sample temperature $\left({ }^{\circ} \mathrm{C}\right), T_{2}$ is final sample temperature $\left({ }^{\circ} \mathrm{C}\right), L$ is latent heat of water evaporation $(\mathrm{kJ} / \mathrm{kg}), m_{i}$ is mass of evaporated water from the sample $(\mathrm{kg})$.

Response Surface Methodology (RSM) and Analysis of variance (ANOVA) were selected to estimate the main effect of the process variables (process time and osmotic solution concentration) on Quantity of heat saved during the process of osmotic dehydration of chicken meat.

The independent variables were process time $\left(\mathrm{X}_{1}\right)$ of 1,3 and $5 \mathrm{~h}$ and concentration of the osmotic solution $\left(\mathrm{X}_{2}\right)$ of 60,70 and $80 \%$. The dependent variable observed was the response: Quantity of heat saved (Y). A model was fitted to the response surface generated by the experiment. The following second order polynomial (SOP) model was fitted to the data:

$$
Y=\beta_{0}+\beta_{1} X_{1}+\beta_{11} X_{1}^{2}+\beta_{2} X_{2}+\beta_{22} X_{2}{ }^{2}+\beta_{1} X_{1}+\beta_{12} X_{1} \cdot X_{2}
$$

where $\beta_{0}-\beta_{12}$ are constant regression coefficients.

Statistical analysis of experimental data was performed using StatSoft Statistica 12 [12].

\section{Results and discussion}

The results of the dynamics of water evaporations are shown in figure 1, where the dependence of time needed for certain levels of WL and values of WL for chicken meat and water samples is formed. Since chicken meat and water samples were dried in parallel runs, 
under the same conditions, it can be assumed that the same quantity of heat by both samples is absorbed.

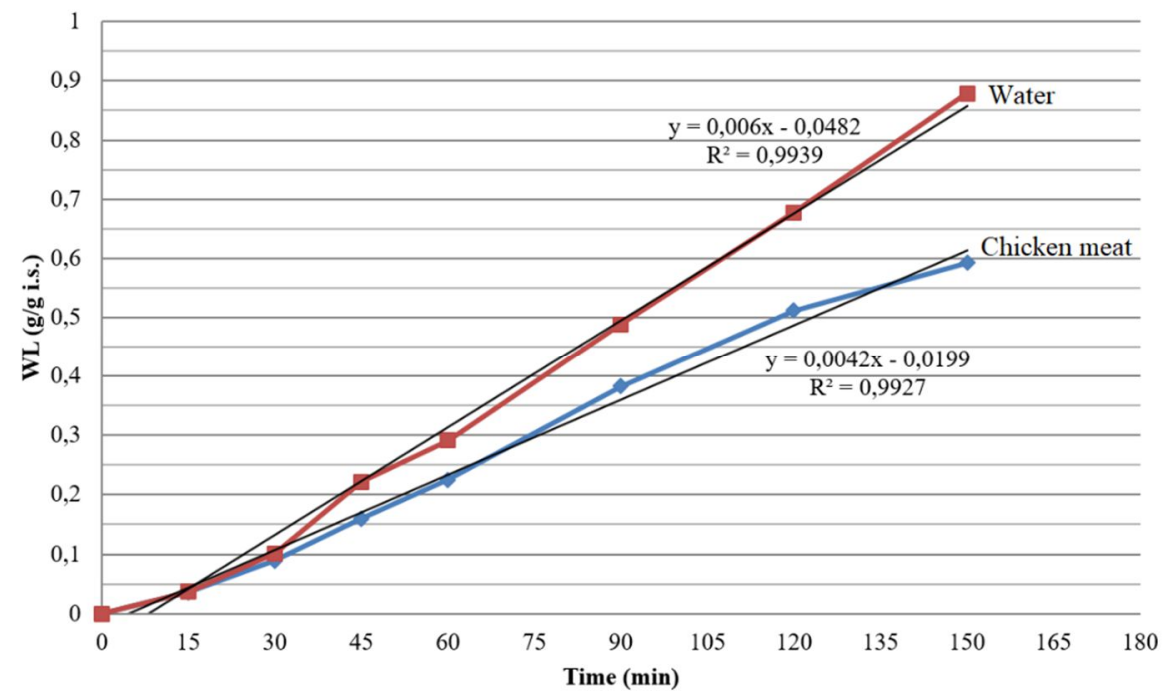

Fig. 1. Dependence of water loss by evaporation from meat and water samples and the duration of convective drying.

Derived equation of dependence of time $(y)$ and WL for chicken meat samples $(x)$, presented on figure 1, were used for calculation of the time of convective drying needed for achieving same WL levels as for different processes of osmotic dehydrations presented in table 1. Then, for the same determined time of convective drying, using the dervied equation of dependence of time $(y)$ and WL for water $(x)$, presented on figure 1 , WL values for water samples were determined. These WL values of water samples are used for calculating the quantity of absorbed heat using equation (1). This quantity of heat is also absorbed by chicken meat samples for achieving observed WL levels. In that way the connection between WL values achieved in osmotic dehydration process and assumed and calculated ,saved" quantity of heat by using osmotic process instead of convective drying is achieved.

Values of ,saved" quantity of heat for chicken meat osmotic processes at different process times and osmotic solution concentrations are presented in table 1 .

From presented results, it can be seen that minimal quantity of saved energy was $1145.35 \pm 19.40 \mathrm{~kJ} / \mathrm{kg}$ of meat, in 1-hour process in molasses of lowest concentration, while the maximal quantity of saved energy was $1825.66 \pm 19.13 \mathrm{~kJ} / \mathrm{kg}$ of meat, in 5 -hour process in molasses of highest concnetration. These obtained values are slightly higher $(3.09 \%)$ in comparison to the respective values of the quantity of saved energy in the process of osmotic dehydration of pork meat [9].

It can also be seen that both the time of the osmotic dehydration process and osmotic solution concentration statistically significantly contributed to the quantity of saved energy. By increasing these technological parameters, the values of quantity of saved energy also statistically significanly increases, as it can be seen from the graphical presentation of the developed mathematical model of the quantity of heat needed for the same level of WL in convective drying of $1 \mathrm{~kg}$ of chicken meat, presented in figure 2 . 
Table 1. Average values and standard deviations of quantities of heat needed for the same level of WL in convective drying of $1 \mathrm{~kg}$ of chicken meat

\begin{tabular}{|c|c|c|c|c|}
\hline $\begin{array}{c}\text { Number } \\
\text { of sample }\end{array}$ & $\begin{array}{l}\text { Time of the } \\
\text { process (h) }\end{array}$ & $\begin{array}{c}\text { Concentration } \\
\text { (\% d.m.) }\end{array}$ & $\begin{array}{c}\text { WL } \\
\left(\mathrm{g} / \mathrm{g}_{\text {i.s. }}\right)[13]\end{array}$ & $\begin{array}{l}\text { Quantity of heat } \\
\text { (kJ/kg of meat) }\end{array}$ \\
\hline 1 & 1 & 80 & $\begin{array}{c}0.3247 \\
\pm 0.0025 \\
\end{array}$ & $\begin{array}{l}1271.72 \\
\pm 13.41^{\mathrm{d}} \\
\end{array}$ \\
\hline 2 & 3 & 80 & $\begin{array}{l}0.4634 \\
\pm 0.011\end{array}$ & $\begin{array}{l}1719.42 \\
\pm 10.59^{\mathrm{f}}\end{array}$ \\
\hline 3 & 5 & 80 & $\begin{array}{l}0.4963 \\
\pm 0.011 \\
\end{array}$ & $\begin{array}{l}1825.66 \\
\pm 19.13^{\mathrm{c}} \\
\end{array}$ \\
\hline 4 & 1 & 70 & $\begin{array}{c}0.2955 \\
\pm 0.0044\end{array}$ & $\begin{array}{c}1177.22 \\
\pm 8.64^{\mathrm{a}}\end{array}$ \\
\hline 5 & 3 & 70 & $\begin{array}{c}0.4478 \\
\pm 0.0046\end{array}$ & $\begin{array}{c}1669.18 \\
\pm 3.19^{\mathrm{b}}\end{array}$ \\
\hline 6 & 5 & 70 & $\begin{array}{c}0,4864 \\
\pm 0.0006\end{array}$ & $\begin{array}{l}1793.80 \\
\pm 25.49^{\mathrm{c}}\end{array}$ \\
\hline 7 & 1 & 60 & $\begin{array}{l}0.2856 \\
\pm 0.014 \\
\end{array}$ & $\begin{array}{l}1145.35 \\
\pm 19.40^{\mathrm{a}} \\
\end{array}$ \\
\hline 8 & 3 & 60 & $\begin{array}{c}0.4147 \\
\pm 0.0068 \\
\end{array}$ & $\begin{array}{c}1562.21 \\
\pm 1.96^{\mathrm{e}} \\
\end{array}$ \\
\hline 9 & 5 & 60 & $\begin{array}{c}0.4506 \\
\pm 0.0016\end{array}$ & $\begin{array}{c}1678.21 \\
\pm 9.62^{\mathrm{b}}\end{array}$ \\
\hline
\end{tabular}

a-f Different letters in superscript in the table indicate statistically significant difference between values, at significance level of $p<0.05$, based on Tukey HSD test
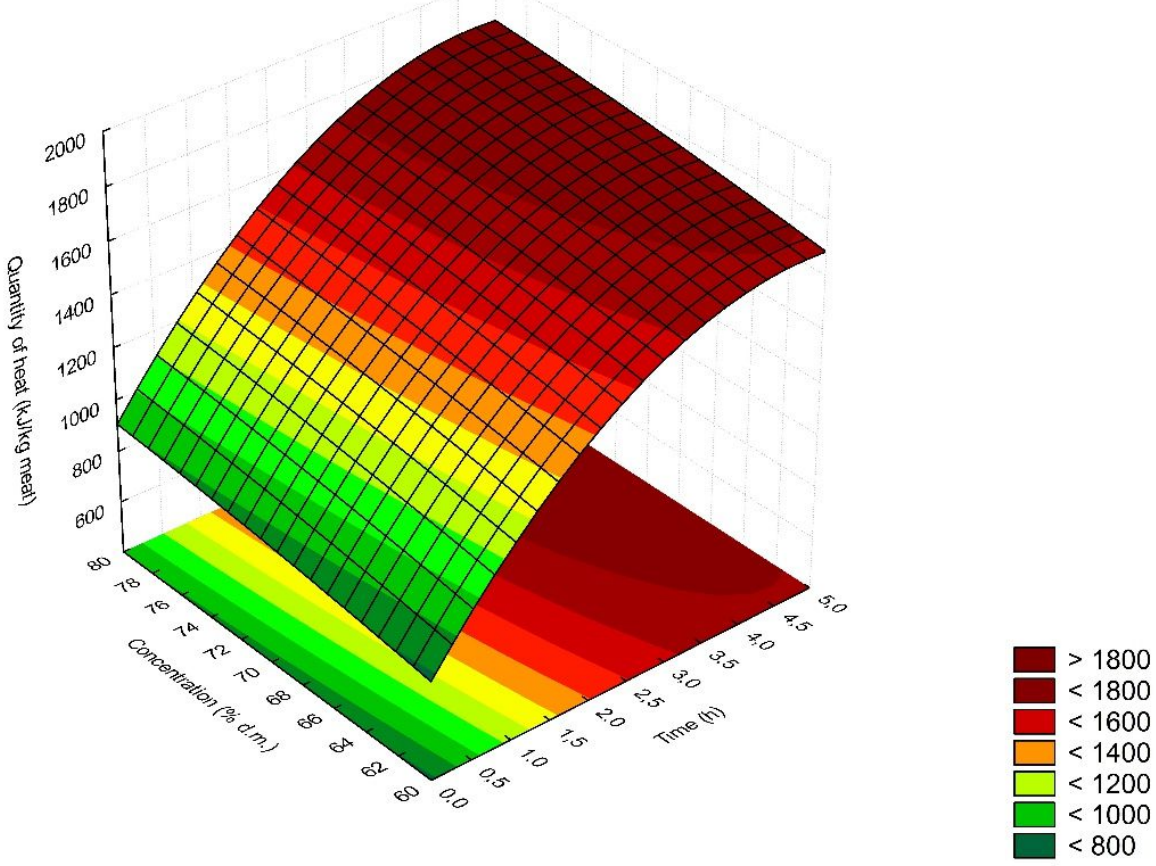

Fig.2. Graphic presentation of the SOP of quantity of heat needed for the same level of WL in convective drying of $1 \mathrm{~kg}$ of chicken meat. 
Table 2 shows the results of ANOVA of the RSM model which was developed on the basis of the experimental results provided in Table 1. In the method, SOP in the form of the equation (2) was used. From presented results, it can be seen that values of Quantity of heat saved in the osmodehydration process were statistically significantly influenced by both technological parameters, where time was a more significant technological parameter, than osmotic solution concentration, which can also be seen from figure 2. SOP quadratic term for time and both SOP linear terms statistically significantly contributed to forming of the model. The residual variance was not statistically significant, indicating that the applied mathematical model was adequate, with a high level of determination coefficient $\mathrm{R}^{2}$ (0.9964), which indicated good fitting of SOP model with obtained experimental values.

Table 2. Analysis of variance of the model of quantity of heat neededfor the same level of WL in convective drying of $1 \mathrm{~kg}$ of chicken meat

\begin{tabular}{|c|c|c|c|}
\hline \multicolumn{2}{|l|}{ Term } & \multirow{2}{*}{$\mathbf{d f}^{\mathbf{1}}$} & Sum of squares \\
\hline & & & Quantity of heat saved \\
\hline \multirow[t]{2}{*}{ Time } & Linear & 1 & $483589.0^{*}$ \\
\hline & Quadratic & 1 & $56634.8^{*}$ \\
\hline \multirow[t]{2}{*}{ Concentration } & Linear & 1 & 30964.3* \\
\hline & Quadratic & 1 & 336.3 \\
\hline Cross product & Time $\mathrm{x}$ Concentration & 1 & 111.1 \\
\hline \multirow[t]{2}{*}{ Error } & Residual variance & 3 & 2159.3 \\
\hline & Total sum of squares & 8 & 573794.8 \\
\hline
\end{tabular}

${ }^{*}$ Statistically significant at level of significance of $\mathrm{p}<0.05$

${ }^{1} \mathrm{df}$ - degrees of freedom

Regression coefficients of the SOP model of the quantity of heat needed for the same level of WL in convective drying of $1 \mathrm{~kg}$ of chicken meat, are shown in table 3 . The statistical significance of all coefficients is also marked.

Table 3. Regression coefficients of SOP of quantity of heat neededfor the same level of WL in convective drying of $1 \mathrm{~kg}$ of chicken meat

\begin{tabular}{|l|c|}
\hline & Quantity of heat saved \\
\hline$\beta_{0}$ & -228.496 \\
\hline$\beta_{1}$ & $375.918^{*}$ \\
\hline$\beta_{11}$ & $-42.069^{*}$ \\
\hline$\beta_{2}$ & 24.548 \\
\hline$\beta_{22}$ & -0.130 \\
\hline$\beta_{12}$ & 0.264 \\
\hline$\beta_{23}$ & -228.496 \\
\hline
\end{tabular}

${ }^{*}$ Statistically significant at $\mathrm{p}<0.05$ level,

\section{Conclusions}

From the presented results it can be concluded that:

- Maximal quantity of heat saved was $1825.66 \mathrm{~kJ} / \mathrm{kg}$ of meat, indicating on high levels of energy efficiency of chicken meat osmodehydration process.

- Both technological parameters statistically significantly influenced process energy efficiency, where process time was more significant technological parameter than osmotic solution concentration. 
- The RSM well described mathematical model, which was statistically significant, while predicted and observed response corresponded very well, allowing good prediction of the quantity of heat saved based on applied technological parameters.

These results are part of project supported by the Ministry of Education and Science of the Republic of Serbia, TR-31055, and 2011-2019.

\section{References}

1. G. Volpato, E.M.Z. Michielin, S.R.S. Ferreira,J.C.C.Petrus, J. Food Eng. 79, 779 (2007)

2. K.J.Chua, A.S.Mujumdar, M.N.A.Hawlader, S.K,Chou,J.C. Ho, Food Res. Int., 34, 721 (2001)

3. N.M.Panagiotou, V.T.Karanthanos,Z.B. Maroulis, Dry. Technol., 17,175 (1999)

4. K.N.Waliszewski, H.D.Cortés, V.T.Pardio, M.A. Garcia, Dry. Technol., 17, 955 (1999)

5. M. Della Rosa and F. Giroux, J. Food Eng., 49, 223 (2001)

6. D. Torreggiani, Food Res. Int., 26, 59 (1993)

7. N.K.Rastogi, K.S. Raghavarao, M.S.Niranjan, D. Knorr, Trends Food Sci. Tech., 13, 48 (2002)

8. A.A. El-Aouar, M.P. Azoubel, L.Jr.J. Barbosa, F.E.X. Murr, J.Food Eng., 75, 267 (2006)

9. V. Filipović, B. Ćurčić, M. Nićetin, V. Knežević, L. Lević, L. Pezo, J. Process. Energy Agric., 18, 218 (2014)

10. L.Pezo, B.Ćurčić, V. Filipović, M.Nićetin, G.Koprivica, N.Mišljenović, Lj.Lević, Hem. Ind., 67, 465 (2013)

11. R.T. Toledo, Fundamentals of Food Process Engineering, (University of Georgia, Athens, Georgia, USA, 2007)

12. STATISTICA (Data Analysis Software System), v.12.0. Stat-Soft, Inc, USA (www. statsoft.com) (2012)

13. V. Filipović, B. Lončar, M. Nićetin, V. Knežević, D. Šuput, T. Kuljanin, II International Congress "Food Technology, Quality and Safety", Novi Sad, Proceedinsgs, 94 (2014) 